\title{
The Development of Autonomous Student Learning Networks: Patterns of Interactions in an Open World Learning Environment for Teachers Exploring Teaching with and through Computer Science
}

\author{
Gerald Ardito $^{1, *(D)}$ and Betül Czerkawski ${ }^{2}$ (D) \\ 1 School of Education, Manhattanville College, New York, NY 10577, USA \\ 2 Department of Applied Technology, The University of Arizona, Tucson, AZ 85635, USA; \\ bcozkan@email.arizona.edu \\ * Correspondence: gerald.ardito@mville.edu
}

Citation: Ardito, G.; Czerkawski, B. The Development of Autonomous Student Learning Networks: Patterns of Interactions in an Open World Learning Environment for Teachers Exploring Teaching with and through Computer Science. Sustainability 2021, 13, 8696. https://doi.org/10.3390/ su13168696

Academic Editors: Nuria

Medina Medina and Francisco Luis Gutiérrez Vela

Received: 12 June 2021

Accepted: 27 July 2021

Published: 4 August 2021

Publisher's Note: MDPI stays neutral with regard to jurisdictional claims in published maps and institutional affiliations.

Copyright: (c) 2021 by the authors. Licensee MDPI, Basel, Switzerland. This article is an open access article distributed under the terms and conditions of the Creative Commons Attribution (CC BY) license (https:/ / creativecommons.org/licenses/by/ $4.0 /)$.
Abstract: This pilot case study sought to investigate patterns of interactions between learners and their instructor in a teacher education course called "Computer Science for Teachers". This course was constructed to leverage aspects of open world game design elements in order to investigate the effects of degrees of autonomy in gameplay/learning. This course was conducted in a specially built social learning platform based on Elgg software. Student interactions with the instructor and other students in this course were analyzed to determine the learning networks students constructed during each key learning activity as well as the epistemic spaces defined by these interactions. Descriptive statistics along with social network analysis (SNA) and epistemic network analysis (ENA) were used to investigate these data. The findings indicate that more traditional/less open world gaming type learning activities were associated with learning networks and epistemic spaces that were teacher-centered and narrower, while more open world gaming/high levels of autonomy (studentcentric) learning activities were associated with learning networks that were highly decentralized and epistemic spaces that featured students asking and answering questions of / for one another. These findings were consistent with existing research into player behavior in open world type games and learner behavior in settings with high levels of autonomy support. Implications for further research are discussed.

Keywords: game design; open world gaming; serious games; game-based learning; instructional design; teacher education; learner autonomy; computer science education; learning design

\section{Introduction}

Games and learning have had a long, adjacent history. In hunter-gatherer and agrarian cultures, children played games that presaged work and cultural norms [1]. This play helped prepare them to be successful adults. The song "London Bridge is Falling Down" and its associated dance/play may have helped children make sense of plague times. Children everywhere seem to create games that help them understand the worlds they occupy. Playing "school," for example, provides children across the world with the means to make sense of and integrate the power dynamics (teachers tell students what to do) and social norms (children sit quietly following the "teacher's" instructions) inherent in their early experiences of schools.

More recently, educators and others interested in education have looked to children's responses to games and gaming, especially video and mobile gaming, with a seeming sense of wistfulness. They have seen students immersing themselves fully in games that offer very complex tasks, working together on missions of all sorts, and being able to deal with large amounts of feedback and data in order to succeed in these games. These insights led to educators and game designers working to "gamify" learning experiences, meaning 
that they added elements of games such as scores, leaderboards, leveling up, badges, etc., directly into learning experiences [2,3]. The addition of these game elements has been particularly common and popular in what is commonly called drillware, software that leads students through rote, "drill and kill" type learning activities, such as Math Blaster.

Another trend in the goal to connect learning and gaming has been the development of "serious" games. "Serious" gaming refers to games that have a clearly educational intent. The main goal of the game is to teach the player something, and the designed learning takes place through the playing of the game itself. Many of these types of serious games fall in the category of simulations of various types. The classic video game Oregon Trail, originally developed in the early 1970s, was designed to give players a sense of the reality of 19th century life. Complex role-playing games, such as the series Reacting to the Past, are designed to allow students to investigate and inquire into key historical events, such as in the scenario "Greenwich Village, 1913: Suffrage, Labor, and the New Woman" [4], in deep and meaningful ways. Science games, such as FoldIt, encourage players to investigate complex scientific phenomena such as protein folding [5]. These serious games typically grant a high degree of autonomy to the players/learners in order for them to engage with and inhabit characters and/or scenarios. These simulations tend to provide players with higher levels of autonomy than more narrowly scripted games [6].

High levels of player/learner autonomy are particularly evident in two other game genres: massively multiplayer online role-playing games and "open world" games. Massively multiplayer online role-playing games (MMORPG), such as World of Warcraft (WOW) and Star Wars: The Old Republic, give players the chance to individually or collaboratively assume roles, characteristics, and powers in order to complete quests or missions in a massive online environment. Open world games, such as Grand Theft Auto, employ a game mechanic that ascribes much more freedom in the ways that players occupy and explore the world and goals of the game. These types of games typically require players to have and develop high levels of strategic thinking and problem solving skills and support real, deep, and authentic learning $[7,8]$.

It is this intersection between high levels of autonomy in both game design and learning, such as is found in open world games as described above, with which this research is interested. We investigated the effects of an open world type learning environment and its associated learning activities on pre-service and in-service teachers in a graduate level educational technology pedagogy course called "Computer Science for Teachers." Specifically, we explored in what ways the degree of autonomy in the gaming/learning environment influenced the types and patterns of interactions between students in the course. Therefore, this research study was designed to explore the following research questions:

1. What patterns of connections and interactions emerge between students and their instructor in a graduate teacher education course designed using elements of open world game design?

2. In what ways does the degree of autonomy designed into key learning activities influence the types and patterns of interactions between the students with one another and their instructor?

\section{Review of the Related Literature}

Central to this research study are player/learner motivation and engagement, the influence of instructional design and game design on the playing/learning environment, and patterns of interactions between learners/players within gaming and learning settings. The relevant research for each is discussed in this section.

\subsection{Motivation and Engagement-Self-Determination Theory}

Motivation and engagement are central to the design of both learning environments and gaming environments. Self-Determination Theory (SDT) has proven to be a powerful framework for understanding the relationship between motivation and engagement in a 
variety of settings. SDT views motivation as a function of the fulfillment or frustration of basic human needs for autonomy (perceived degree of being volitional), competence (perceived degree of efficacy), and relatedness (perceived degree of connectedness) [9]. Settings where these needs have been positively correlated with high degrees of intrinsic motivation and overall satisfaction, and settings where these needs are frustrated, have been positively correlated with low levels of intrinsic motivation and overall satisfaction $[10,11]$. This powerful framework for understanding motivation and engagement has been applied to many fields of human endeavor, including healthcare [12], organizational leadership [13], religion [14], and technology [15]. SDT research has also been conducted into motivation and engagement in both learning and gaming environments. This research has focused on learner autonomy and competence supportive learning and gaming design elements.

In learning settings, SDT research has investigated the connections between degrees of autonomy and competence support from teachers and their effects on learners' perceived autonomy, perceived competence, and learning outcomes. These studies have consistently demonstrated strong positive relationships between autonomy and competence supportive learning environments and learner motivation, engagement, and learning [16-18]. These findings are well summarized by Niemiec and Ryan:

Several important conclusions can be drawn from these and related findings on intrinsic motivation. First, both teachers' orientations and specific aspects of learning tasks that are perceived as autonomy supportive are conducive to students' intrinsic motivation, whereas controlling educational climates undermine intrinsic motivation. Second, students tend to learn better and are more creative when intrinsically motivated, particularly on tasks requiring conceptual understanding. Third, the way in which teachers introduce learning tasks impacts students' satisfaction of the basic psychological needs for autonomy and competence, thereby either allowing intrinsic motivation to flourish and deeper learning to occur or thwarting those processes. [19] (p. 136).

SDT research has also been conducted in the areas of games and gaming. This research echoes the findings from that focused on education and learning. Games can use elements that manipulate levels of extrinsic motivation (rewards, badges, etc.) in order to, for example, increase playing time [20]. However, a great deal of research has indicated that elements that promote player autonomy (by providing authentic choices) and competence (by providing positive feedback) have a far higher positive relationship with player satisfaction and engagement $[6,20,21]$.

Although all of the autonomy-supportive and competence-supportive features we manipulated have been adopted in many successful video games by designers and developers intuitively, our findings suggest that well-established theories can prescribe a systematic guideline for design choices, which goes beyond the intuitive seat-of-the-pants reasoning. This is especially important for researchers who plan to harness the motivating power of video games for health and education interventions [21] (p. 192).

Further, this sense of efficacy and mastery has been correlated with an increased experience of competence and satisfaction on the part of the gamer [22]. The findings of this research reveal strong positive relationships between the degree of autonomy (more autonomy support vs. more control) and the feedback valence (degree of positive or negative feedback) in gaming environments and increased experience of player competence and intrinsic motivation.

Sylvester Arnab and his colleagues have established a typology of game mechanics and game design elements in terms of the degree of autonomy and competence support they are likely to provide [23]. In this typology, game elements such as highly directed progressions through a game and action points and rewards/penalties are associated with low levels of autonomy and competence, while other game elements such as collaboration, communal discovery, and strategy/planning are associated with higher levels of autonomy and competence [23] (p. 92). Therefore, the design of the gaming environment, as with the 
design of the learning environment, is critical to the player's/learner's perceived autonomy and competence.

\subsection{Game Design and Instructional Design}

Instructional design (ID) is a systematic design process based on what we know about learning theories, information technology and educational research [24]. Traditionally, ID requires a complete plan and arrangement of the course or even a program using carefully thought-out procedures. In recent years, with the advance of new technologies and ubiquitous forms of e-learning modalities, traditional and linear ID have been replaced with "learning design", where small-scale experiences for learners are planned in a recursive fashion in a less prescribed manner (in this text, we use instructional design and learning design interchangeably while actually referring to "learning design").

Instructional or learning design of games usually occurs in two ways: gamification and the use of commercial or serious games. Gamification is a teaching strategy rather than a broadly understood instructional design and development approach. The purpose of gamification in education is to create experiences and motivations as games do. In gamification, course activities are arranged so that difficulty levels can be adjusted based on learner needs, or learners receive awards (i.e., badges) as a means of a certain course achievement. In other words, there are no actual games played, but elements of gameplay are integrated in the course activities [25]. With commercial or serious games, learners play the game individually or as a group to achieve learning outcomes. In this approach, games are not only used as a teaching strategy, but they have an impact on the entire design of the teaching and learning process. In recent years, this approach became more prevalent than gamification, while mobile technologies are used more and more to facilitate gameplay [26].

Gamification as a teaching strategy is well-established in education research [27]; however, "this vein of research has mainly advanced without an agenda, theoretical guidance or a clear picture of the field" [28]. Hence, learning design perspective was never brought into the education environments, but a few gaming factors were used in the course design. When serious games are used for educational purposes, they are better integrated into course design, but the research focus with serious games has always been either on the game design itself [29] or the gameplay [30,31]. It is the authors' hope that the present study will bridge this gap in the literature by bringing a more holistic approach to course design with games.

\section{Materials and Methods}

This research was designed to be a pilot case study to both demonstrate some initial findings as well as finalize the methods of data collection and analysis for a four-year, longitudinal study. This section outlines the structure of this initial study.

\subsection{Context and Participants}

The participants for this pilot case study were the instructor and the 14 students enrolled in a one semester graduate course for teachers and teacher candidates entitled "Computer Science for Teachers." The focus of this course was to present these current and future educators with an historical background of computers and computer science in education as well as developing both content and pedagogical knowledge for the teaching and learning of the key concepts of Computational Thinking (CT) and Computer Science (CS).

This course was conducted asynchronously online via a custom-built social learning platform constructed using open source Elgg social networking software. Like other social networking software, Elgg allowed course participants to create blog posts and share photos, videos, and links to other websites. They were also able to leave comments for one another on anything that had been shared. The focus of this social learning platform was openness, and participants had multiple, mixed-media ways of expressing themselves and 
communicating with one another. This design was consistent with research into both open learning environments [32] and open world gaming environments [33].

\subsection{Course Design as Game Design}

The CS for Teachers course was designed as a set of three interconnected units: Software takes Command: A history and future of computer science, in which the students explored some of the history of CS in education and some early tools for doing so, such as Etoys; Code is Poetry: An introduction to programming languages and logic, in which the students worked to learn a text-based programming language (HTML or Python) in order to understand how such languages work and how to debug programs; and Break It to Make It: Learning about maker spaces through robotics, in which students worked with an inexpensive but powerful robotics kit, the mBot, through which they developed some proficiency in programming the behavior of a physical object and its various sensors by meeting two challenges. The first, the Dance-Off challenge, required students to program their robots to dance for at least two minutes to a song of their choice. The second, the Dealer's Choice challenge, required students to design a coding project that demonstrated all of what they had learned about programming their robots. Additionally, at the end of the course, students were asked to put together a portfolio of their best work, along with a reflection discussing what they learned over the semester.

Each of these units have a key learning activity, which was designed to correlate with elements of game design as articulated by Arnab's typology [23] (p. 92).

Two of the learning activities, Read/Respond and Final Portfolio and Reflection, involved game elements (highly directed progressions) with lower levels of autonomy. The Robot Coding activities involved game elements (collaboration, communal discovery, and strategy/planning) with high levels of autonomy. Finally, the Learning Logs featured a mix of the two.

\section{Learning Design}

In our research, we employed principles of learning design in the following ways:

- Focused and clear learning goals: Before starting each activity in the course (see Table 1), students were informed of the learning goals and expectations. The main purpose of the gameplay is usually entertainment (especially when commercial games are used for educational purposes), so in order to receive maximum educational benefits, the instructor clearly explained how the games will be used in the course and how it will benefit the learners. At the end of the study, an alignment between learning objectives and outcomes was carefully established.

- Setting and Actions: In a successful learning design, learners are informed of the characters in the game, its settings, environmental dimensions such as geography, historical context, and appearance. The instructor of the course provided this information to the students in advance so they would not lose focus or become distracted while searching for information.

- Instructional Support: The role of the instructor was an important variable in the present study, so special attention was paid to when and how the instructor interfered in the gaming activities. An initial explanation and orientation by the instructor was followed by student-centered gaming activities.

- Learner autonomy: When it comes to learning design for game-based learning, "the learner plays an active role in the construction of knowledge, while the role of the teacher is to provide materials and an environment that support the learner's engagement in the learning tasks" (Dickey, 2005, p. 78). In our design, students actively engaged in the gaming activities and the course instructor only guided them while they were involved in the gameplay. Students were given opportunities to discover the game among themselves with no instructor interference. This approach resulted in a high level of collaboration, with students giving each other feedback and discussing issues they faced in the game environment in a more active and engaged way. 
Table 1. Learning activities and related levels of game-like openness/autonomy.

\begin{tabular}{|c|c|c|}
\hline Unit & Key Learning Activity & Arnab Taxonomy Components 1 \\
\hline Software Takes Command & Read/Respond & Highly directed progressions (lower autonomy) \\
\hline Code is Poetry & Learning Logs & $\begin{array}{l}\text { Highly directed progressions (lower autonomy) } \\
\text { Discovery (higher autonomy) }\end{array}$ \\
\hline \multirow{3}{*}{ Break It to Make It } & Robot Coding & \\
\hline & $\begin{array}{l}\text { - Dance-Off challenge } \\
\text { - } \quad \text { Dealer's Choice challenge }\end{array}$ & \\
\hline & $\begin{array}{l}\text { Collaboration, communal discovery, } \\
\text { and strategy/planning (higher } \\
\text { autonomy) }\end{array}$ & \\
\hline Putting it All Together & Final portfolio and reflection & $\begin{array}{l}\text { Collaboration, communal discovery, and } \\
\text { strategy/planning (higher autonomy) }\end{array}$ \\
\hline
\end{tabular}

$$
{ }^{1} \text { [23] (p. 92). }
$$

\subsection{Data Collection and Analysis}

\subsubsection{Student/Instructor Interaction Data}

The data collected for this study included all postings (blogs, photos, URLs, and comments) made by the students and the instructor. These interactions were organized into conversations. These conversations linked together the original posts and all associated responses and were associated with the learning activity of the course in which they took place. Figure 1 depicts a small sample of these data. Descriptive statistics, such as frequencies, means, and percents, were performed on these interaction data in order to determine numbers and types of student and instructor postings during each segment of the course.

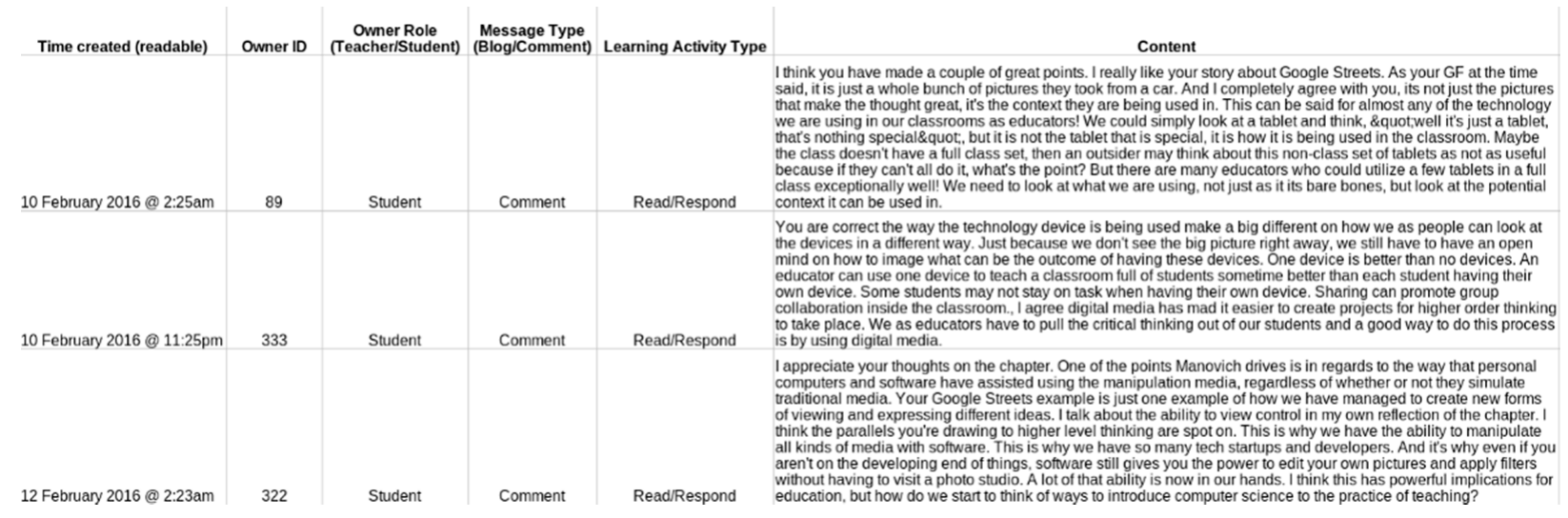

Figure 1. Sample of course interaction data.

\subsubsection{Data Analysis-Social Network Analysis}

Social Network Analysis (SNA) was employed in order to investigate and visualize the social networks that emerged during each learning activity in the course. SNA is a tool that allows researchers to visualize connections between people and has been used to investigate a variety of settings [34,35]. SNA has also been used to explore social networks of players within games, especially in MMORPG and open world games [36,37].

SNA allows researchers to identify, investigate, and visualize the connections between participants in a network, as well as the degree of influence (centrality) held or not held by those participants. There are three broad categories of centrality in SNA research: degree centrality, which identifies the number of connections held by each participant (node) in a network; betweenness centrality, which identifies how often a node lies on the shortest path 
between the other nodes; and closeness centrality, which identifies the relative distance or closeness between nodes in a network [34].

Since this study focused on the influence the course participants had on one another, we investigated information centrality, a hybrid measure of centrality that calculates the degree of influence over the flow of information between actors in a network [38], and a Fruchterman and Reingold force-directed placement algorithm was utilized to enhance the readability of each social graph [39]. In this study, SocNetV, a social network visualization tool, was used to generate these social graphs [40].

\subsubsection{Data Analysis-Epistemic Network Analysis}

The content of the interactions between participants in the course was also analyzed. These interactions were categorized, initially, using an open coding approach [41]. The coding scheme was further refined until a final codebook was established. This codebook, depicted in Table 2, looked at the type of interaction (initial posting vs. responses/comments), the length of any responses (brief vs. extended), and the direction of questions and the answers provided to them (asked of/answer by the instructor vs. asked of/answered by other students). Two coders participated in this process and their inter-rater reliability was $95 \%$. Descriptive statistics were calculated for each of these codes.

Table 2. Final codebook for this study.

\begin{tabular}{|c|c|c|}
\hline Code & Description & Example \\
\hline MM & $\begin{array}{l}\text { Making Meaning-Student } \\
\text { posts work }\end{array}$ & "Here is my final reflection for the course" \\
\hline FT & $\begin{array}{l}\text { Feedback from } \\
\text { teacher-Teacher provides } \\
\text { feedback on student work }\end{array}$ & "This is very insightful." \\
\hline SBR & $\begin{array}{l}\text { Student response (brief) to } \\
\text { another student }\end{array}$ & $\begin{array}{c}\text { "Thank you for allowing me to open up my } \\
\text { understanding about computer science and why } \\
\text { it is needed." }\end{array}$ \\
\hline SER & $\begin{array}{l}\text { Student Extended } \\
\text { Response-student offers } \\
\text { substantive response to } \\
\text { another student's post }\end{array}$ & $\begin{array}{l}\text { "I agree that this stuff can be tough. I seem to get } \\
\text { caught up trying to adjust one minor detail for } \\
\text { an hour at a time. It would be cool if you could } \\
\text { have a slider to adjust the power of the throw, or } \\
\text { one that adjusted the equation for gravitational } \\
\text { pull. (you might be able to find something like } \\
\text { this that someone else has already built)." }\end{array}$ \\
\hline STQ & $\begin{array}{l}\text { Student asks teacher a } \\
\text { question }\end{array}$ & $\begin{array}{l}\text { "What is the best way to share content with the } \\
\text { group?" }\end{array}$ \\
\hline SSQ & $\begin{array}{c}\text { Student asks student a } \\
\text { question }\end{array}$ & $\begin{array}{c}\text { "What courses do you currently teach at the high } \\
\text { school level? How was your second year of } \\
\text { teaching going compared to your first?" }\end{array}$ \\
\hline TAQ & Teacher answers question & "Sharing your work via a blog post is fine." \\
\hline SAQ & $\begin{array}{l}\text { Student answers student } \\
\text { question }\end{array}$ & $\begin{array}{c}\text { "You can use QuickTime to record a screencast of } \\
\text { your Etoys project and then upload it to } \\
\text { something like YouTube" }\end{array}$ \\
\hline
\end{tabular}

Epistemic Network Analysis (ENA) was utilized to explore and make sense of the content of the interactions between participants during the course learning activities. ENA is a quantitative analysis method that allows the researcher to investigate and visualize the epistemic spaces represented by the networks of codes identified in the data, and has been used to help answer a wide range of research questions [42,43]. Most pertinent to this study, ENA has been used to investigate the interactions between students in learning settings [44], as well as the interactions between players in a game [45].

Social graphs and visualizations of the epistemic spaces for the course interactions were constructed for four learning activities in the course: Read/Respond, during which students in the course were responding to relevant texts and to one another's responses; 
Learning Logs, where students shared their process in learning to code in either HTML or Python; Robot Building/Coding, during which students built and then programmed their robots to meet the dance off and dealer's choice challenges described above; and Reflection, during which the students posted their final reflection on the course and on what they considered their best work. These activities were chosen in order to reflect different degrees of autonomy/openness, with Reflection having the least amount of openness and Robot Building/Coding having the greatest amount.

\section{Results}

To investigate the research questions, the patterns and content of the course interactions between the instructor and the students were analyzed. This section discusses those results.

\subsection{Patterns of Course Interactions}

Table 3 presents the descriptive statistics of the frequencies of course interactions during each of the four key learning activities by course role (student vs. instructor).

Table 3. Descriptive statistics of course interactions for each key learning activity.

\begin{tabular}{cccccc}
\hline Key Learning Activity & \# Student Posts & \% Student Posts & \# Instructor Posts & \% Instructor Posts & Total Posts \\
\hline Learning Log & 46 & $79 \%$ & 12 & $21 \%$ & 58 \\
Read/Respond & 130 & $87 \%$ & 20 & $13 \%$ & 150 \\
Reflection & 14 & $50 \%$ & 14 & $50 \%$ & 28 \\
Robot Coding & 151 & $86 \%$ & 24 & $14 \%$ & $17 \%$ \\
Totals & 341 & $83 \%$ & 70 & 411 \\
\hline
\end{tabular}

By design, for most of the key learning activities, the students' posts and responses occurred far more frequently than those by the instructor. The exception is the Reflection activity, where the instructor and the students had an equal share of the interactions. The students posted their work and the instructor provided feedback. In the other three key learning activities, the students contributed at least $79 \%$ of the posts, indicating that student-student interactions were much more frequent and important in this course. Given the small $n$, we did not calculate the possible statistical significance of these findings.

\section{Emergent Social Networks}

Social Network Analysis (SNA) was used to construct social graphs for four learning activities in the course: Read/Respond, during which students posted responses to foundational texts (and to one another); Learning Logs, during which students posted their progress in learning to code in either HTML or Python; Robot Coding, during which students posted their process and products in meeting the two robotics challenges (the dance-off and dealer's choice challenges); and Reflection, during which students posted their final portfolio and reflection of the course.

This section will display and discuss the social graphs that represent the networks present during each of these learning activities. In each of these social graphs, the instructor is represented by a red circle, and the students are represented by circles of different colors. Both the size of the circles as well as their color indicate different levels of information centrality. The larger the circles, the higher the level of information centrality of that node (participant) in that network. Circles of the same color indicate the same level of information centrality.

Figure 2 visualizes the network that emerged during the final Reflection activity. The graph indicates that students interacted with only the instructor in a highly directed manner, meaning that the students posted their work and the instructor responded. 


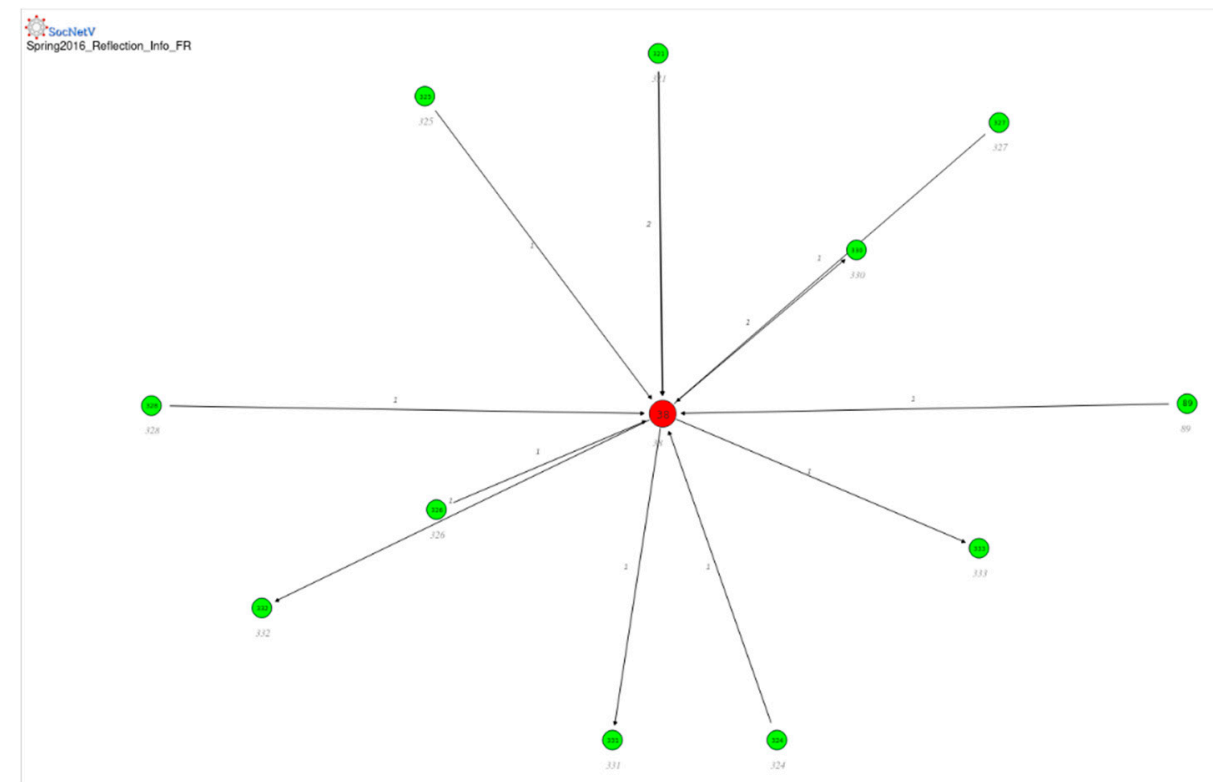

Figure 2. Social network graph for the final Reflection learning activity.

This type of network is typically classified as being highly centralized, meaning that one node is central to all the others.

Figure 3 visualizes the network that emerged during the Learning Log learning activity, during which students shared their progress in learning to code in either HTML or Python. This social graph depicts the students as being connected as a series of groups (dyads or triads), with some additional connections between some of those groups. The instructor and the student represented by the orange circle serve as those connectors. This type of network is less centralized than that depicted in Figure 2 because of those cross-group connections.

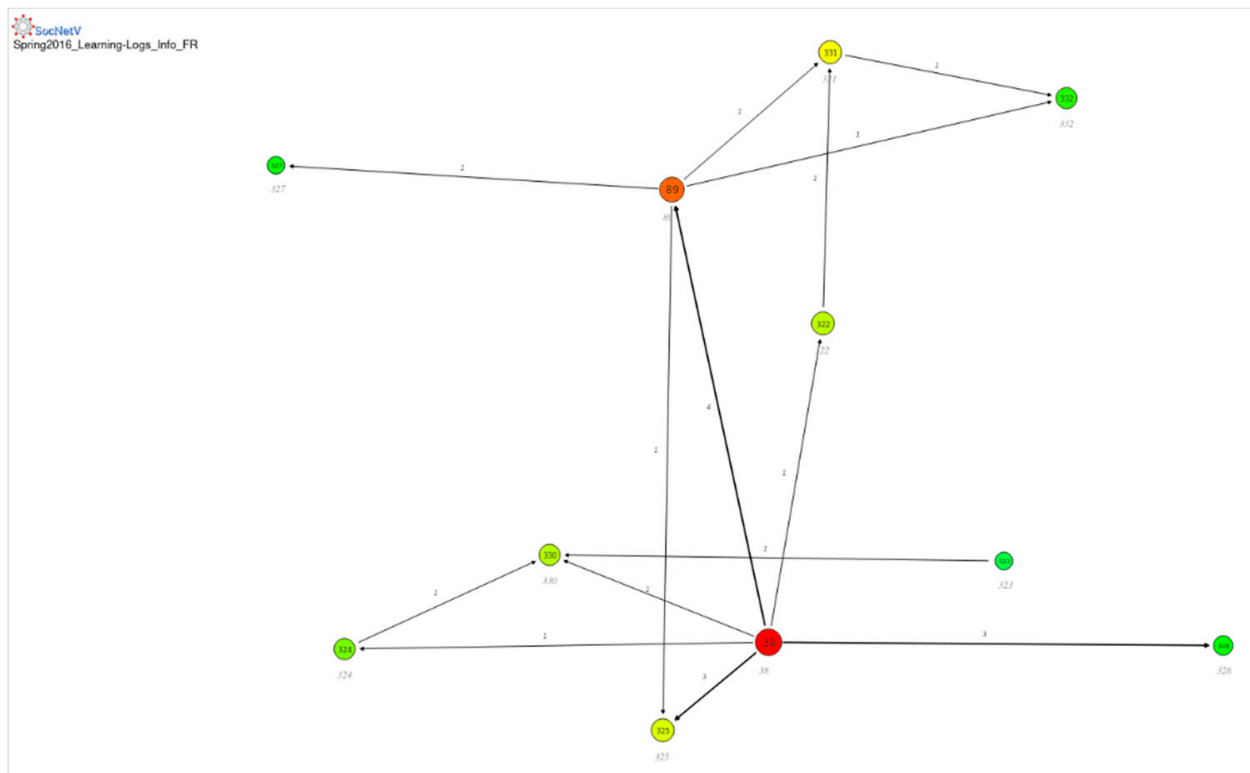

Figure 3. Social network graph for the Learning Log learning activity.

Figure 4 visualizes the network that emerged during the Reading/Respond learning activity, during which the students shared their responses to the foundational texts. This social graph depicts more interactions between more students than in either of the other two discussed thus far. Additionally, several more students, those depicted by orange and 
yellow circles, eight in total, share almost the same degree of information centrality as the instructor. The network depicted in Figure 4 is even more decentralized than that in either Figure 2 or Figure 3.

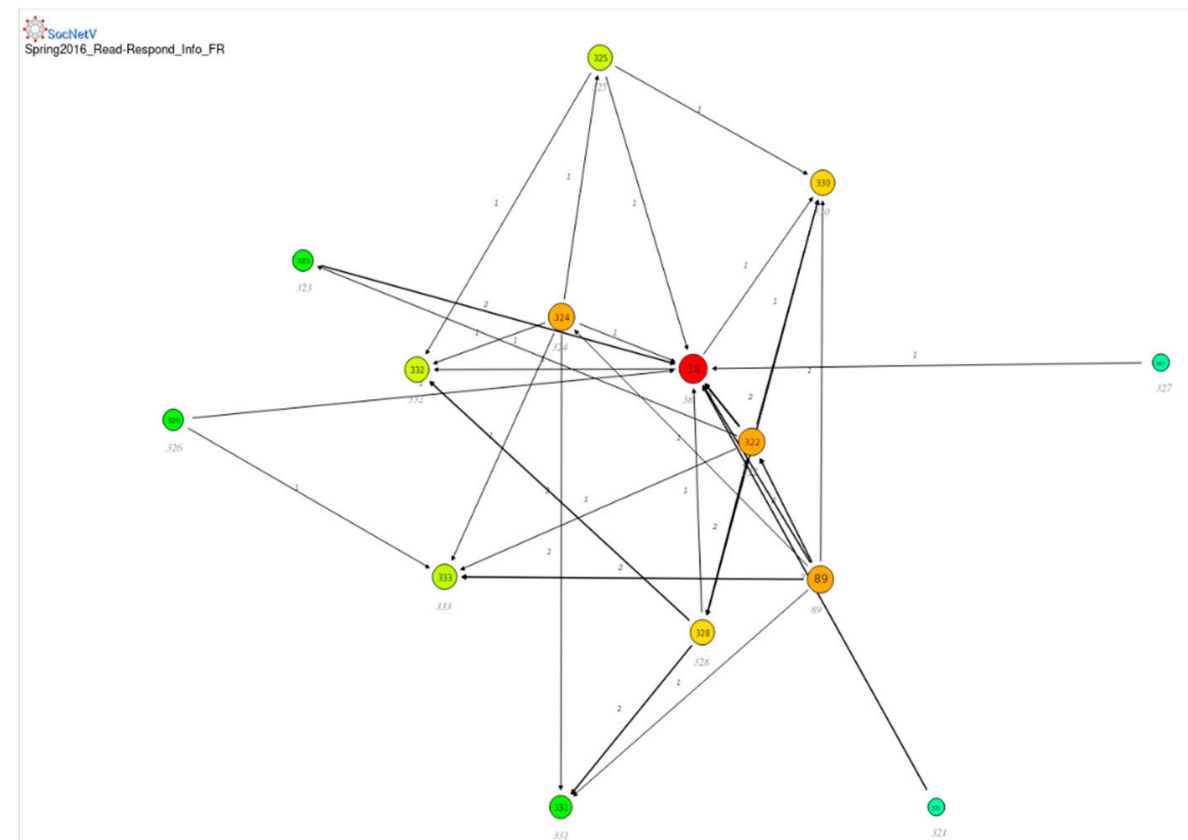

Figure 4. Social network graph for the Read/Respond learning activity.

Finally, Figure 5 visualizes the network that emerged during the Robot Coding learning activity, during which the students learned to program their robots in order to meet the requirements for the dance off and dealer's choice challenges. In this social graph, all the students but three (again those represented by orange and yellow circles) are tightly connected in ways not seen during the other learning activities. Additionally, these students (those with the yellow and orange circles) share a common and high level of information centrality, matching that of the instructor. Of the social graphs discussed so far, this one depicts the most decentralized network.

\subsection{Content of Course Interactions}

After the coding of the course interactions was completed using the codebook in Table 2, descriptive statistics on the presence and frequency of the various codes were determined. They are presented in Table 4.

Table 4. Descriptive statistics of course interactions for each key learning activity.

\begin{tabular}{cccccccccc}
\hline $\begin{array}{c}\text { Key Learning } \\
\text { Activity }\end{array}$ & \# MM & \# TF & \# TAQ & \# STQ & \# SAQ & \# SSQ & \# SBR & \# SER & Total \\
\hline Learning Log & 31 & 12 & 0 & 2 & 0 & 2 & 12 & 2 \\
Read/Respond & 96 & 19 & 0 & 0 & 0 & 1 & 29 & 51 \\
Reflection & 13 & 14 & 0 & 0 & 0 & 0 & 1 & 8 & 28 \\
Robot Coding & 77 & 18 & 1 & 0 & 16 & 20 & 36 & 10 & 178 \\
Totals & 217 & 63 & 1 & 2 & 16 & 23 & 73 & 17 \\
\hline
\end{tabular}

These code frequencies confirm some of the patterns of interactions we found in the course interaction data. During the Reflection activity, we see the students posting work (MM) and the teacher providing feedback (FT). Additionally, we can see that the primary content during the Read/Respond and Learning Log activities is students making brief responses (SBR) to one another. Lastly, during the Robot Coding activity, students are 
asking and answering questions of/to one another. Given the small n, we did not calculate the possible statistical significance of these findings.

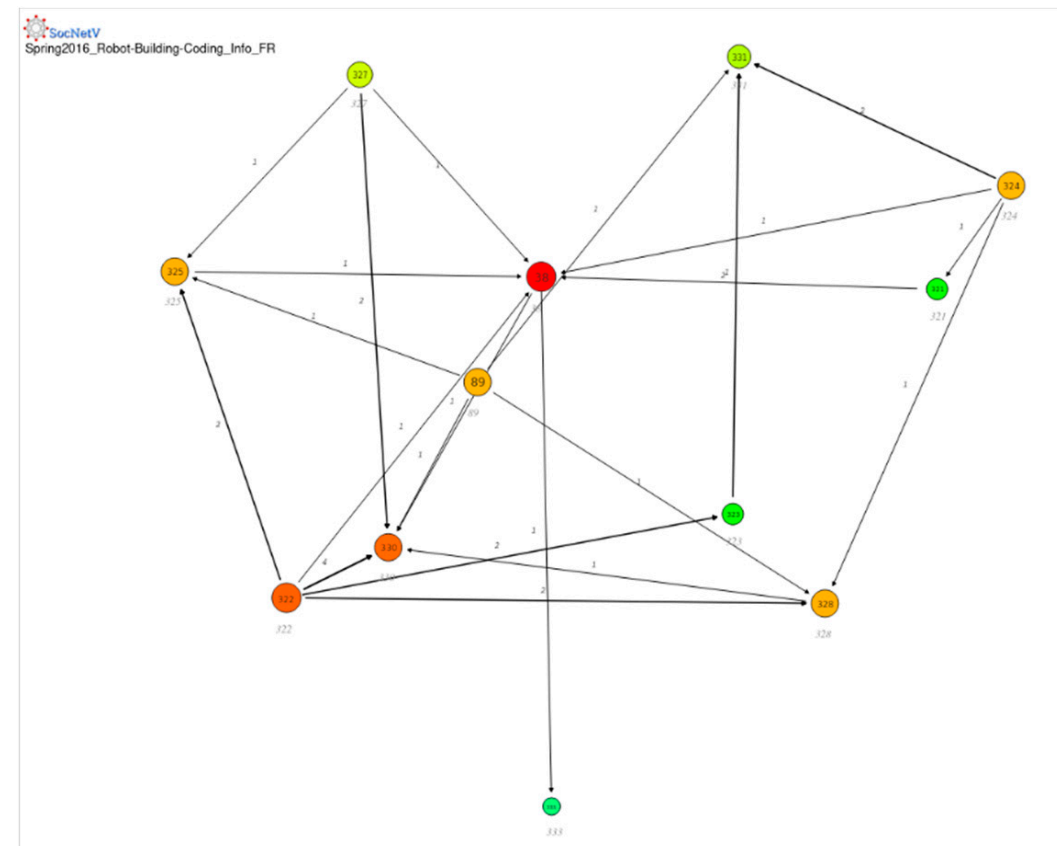

Figure 5. Social network graph for the Robot Coding learning activity.

\section{Epistemic Spaces}

Epistemic Network Analysis (ENA) was employed to extend this frequency analysis of the coding by exploring and then visualizing the epistemic spaces related to each of the four key learning activities of the course. This section will display and discuss the ENA graphs that represent these epistemic spaces. In each, there is a grid in which the networks of codes identified in the course interactions are laid out.

Figure 6 visualizes the epistemic space of the Reflection learning activity. The wide, dark line in the lower left-hand quadrant represents an epistemic space dominated by students posting work (MM) and the instructor providing feedback (FT). This is consistent with the pattern observed in the coding frequency data, as we might expect.

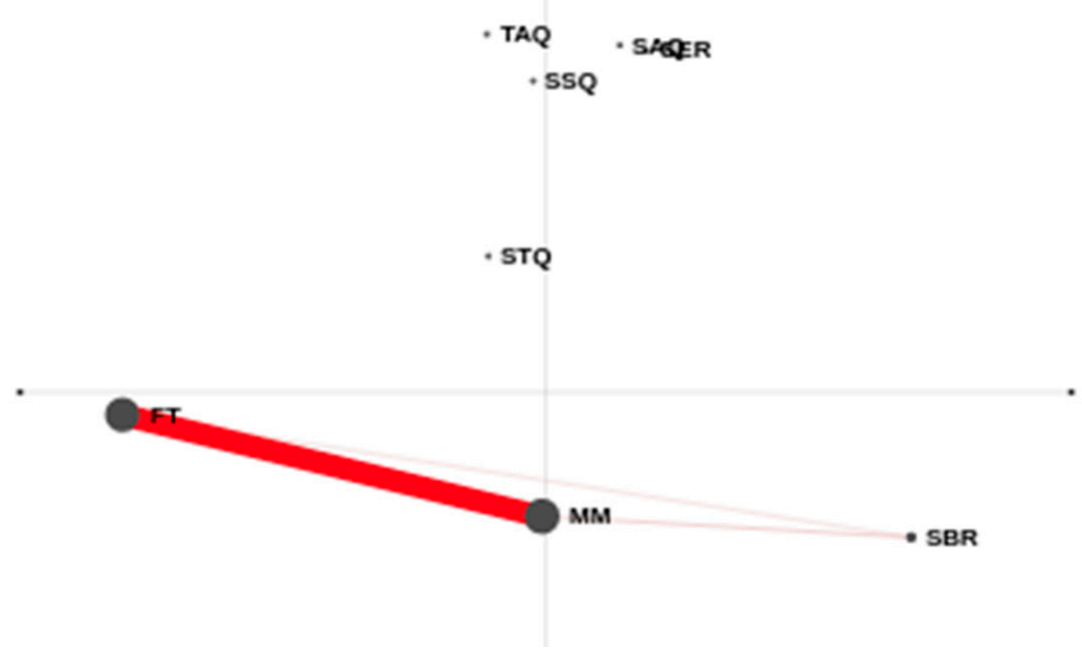

Figure 6. Epistemic network graph for the Reflection learning activity.

Figure 7 visualizes the epistemic space of the Learning Log learning activity. Most of 
this epistemic space includes the students posting work (MM) and the instructor providing feedback (FT). However, there is also a dimension present of students responding briefly to one another (SBR). There are no questions asked of the instructor or the other students, nor are there any questions answered by the instructor of the other students.

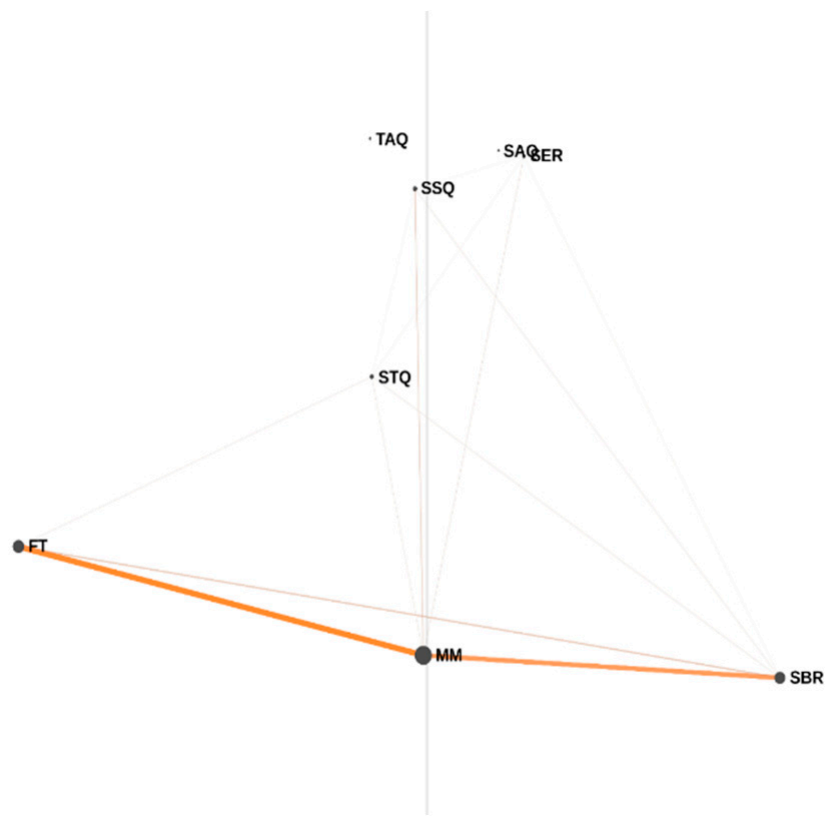

Figure 7. Epistemic network graph for the Learning Log learning activity.

Figure 8 visualizes the epistemic space of the Read/Respond learning activity. As with the ENA graph for the Learning Log activity, the majority of this visualization is occupied by the student posting work (MM)-instructor feedback (FT)-brief student response (SBR) pattern as seen above. However, the epistemic space for this learning activity also includes some extended student responses (SER), indicating that students engaged in discussions with one another around their commentary on the course texts.

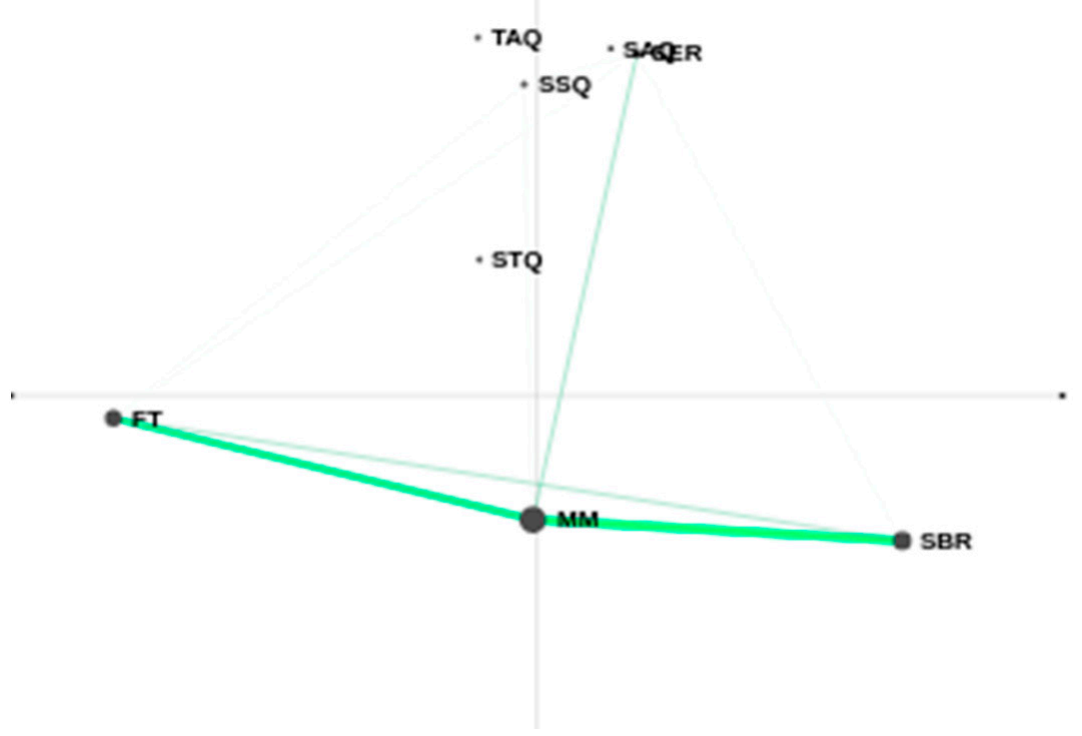

Figure 8. Epistemic network graph for the Read/Respond learning activity.

Finally, Figure 9 visualizes the epistemic space of the Robot Coding learning activity. 
As with the previous two ENA graphs, this one contains the MM-FT-SBR dimension, although it does not make up as much of this graph as the other two, as indicated by the width of the lines. Additionally, there is a new dimension to the epistemic space for this learning activity. Namely, the vertical lines indicate the asking/answering questions components-students asking questions of the instructor (STQ), the instructor answering questions (TAQ), and students asking (SAQ) and answering (SSQ) questions of one another. This additional dimension indicates that students are collaborating in ways not seen in any of the other three key learning activities. This is worth noting since this learning activity, by design, included the largest amount of learner/player autonomy, as indicated by the Arnab taxonomy.

\section{Discussion}

This study sought to investigate the patterns and content of interactions between students and their instructor in a graduate course for teachers and teacher candidates entitled "Computer Science for Teachers". By design, the key learning activities for the course were constructed using game design principles, especially those involving more or less player autonomy as indicated by the taxonomy created by Arnab [23]. In ascending order of increasing player/learner autonomy, they are: Reflection, Learning Logs, Read/Respond, and Robot Coding. The course interactions for each of these four key learning activities were investigated for patterns, primarily in the form of the corresponding social networks that emerged during each activity, and for content, primarily in the form of the corresponding epistemic spaces that arose from their coding.

In addition to the game design principles, this study used a learning design approach when integrating games into course design. More specifically, researchers aligned learning objectives with the learning outcomes, informed learners of the learning goals, employed a learner-centered teaching strategy to increase student autonomy, provided instructional support without interfering with gameplay, and finally thought carefully about teacher and student roles during the implementation phase. The study findings have revealed some trends related to the research questions.

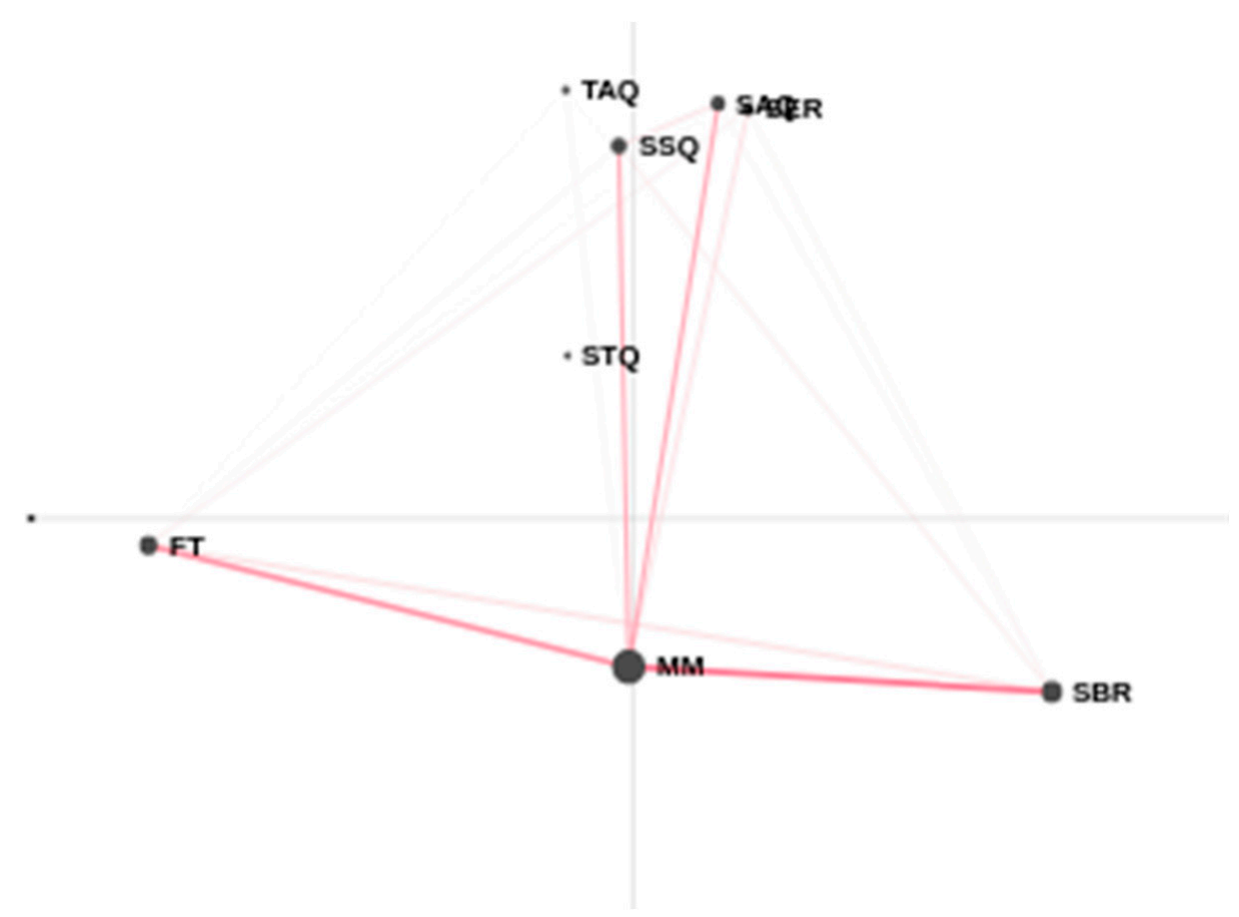

Figure 9. Epistemic network graph for the Robot Coding learning activity.

First, there is a positive relationship between the social networks that emerged during each key learning activity and their relative degree of player/learner autonomy. Those 
activities with the least amount of autonomy (Reflection and Learning Logs), where there was more focus on highly directed progressions, produced social networks that were more centralized. On the contrary, the activity with the highest degree of autonomy, Robot Coding, with its high levels of collaboration, communal discovery, and strategy/planning, produced a social network with the highest level of decentralization. Put another way, there is a positive relationship between the degree of autonomy in the key learning activity and the distribution of information centrality with the associated social network. The more autonomy in the learning activity, the more influence in the network is accomplished by the learners.

Second, there is a positive relationship between the epistemic spaces that emerged during each key learning activity and their relative degree of player/learner autonomy. The activity with the lowest level of autonomy (Reflection) had the narrowest epistemic space and one that focused almost exclusively on students posting work and the instructor providing feedback. The activities with hybrid amounts of autonomy (Learning Logs and Read/Respond) had a slightly wider epistemic space, which was expanded beyond that of the Reflection activity to include students providing brief responses to one another, a sort of balance between what we might expect from highly directed progressions and some collaboration and communal discovery. Robot Coding, the key learning activity with the highest degree of autonomy, was associated with a much wider and deeper epistemic space, and one that added the dimension of the asking and answering of questions, primarily between students.

Third, when instruction was planned with a learner-centered design approach, students started spontaneously collaborating with each other more, interacting more and exploring together during the various key learning activities. Conversely, social network analysis showed that instructor-centric learning activities resulted in a more centralized interaction network where there was little to no interaction between students. Although this study did not focus on comparing learning outcomes of instructor-centered or learnercentered learning design approaches, it became very clear that students progressed faster towards learning outcomes and were engaged more fully in the learning experiences when they were given autonomy over their learning. Future research studies can focus on the various learning design approaches with games to explore these findings further.

These findings strongly suggest that elements and principles of game design can be used creatively and productively to influence instructional design beyond the narrow sense implied by gamification. They also suggest that there is a strong relationship between degrees of autonomy and student influence within a course, which has wide implications for teacher education. Further research is under way to validate and extend these findings.

These findings are consistent with research conducted on player interactions in open world type games. Players in massively multiplayer online role-playing games (MMORPG) tend to form themselves into and interact through purpose-focused groups, such as squads or guilds, which has been demonstrated by social network analysis [46-50]. Research into this player behavior has suggested that this phenomenon is strongly influenced by the design of the game itself: "Player behaviors and group behaviors varied due to game goals, personal preferences, and player awareness, even in the relatively formal barracks-like raiding guilds" [49] (p. 357).

In the current study, these player guilds (purposeful associations of players that support meaningful gameplay) are analogous to the increasingly decentralized social networks organized around information centrality, particularly those associated with the Read/Respond and Robot Coding learning activities. We believe that the epistemic spaces depicted in Figures 8 and 9 featuring increasing dimensions of brief and extended responses as well as the emergent expertise network defined by asking and answering questions form the equivalent of a cognitive guild for these graduate students and that this phenomenon is due, at least in part, to the high degree of autonomy in the game design/learning design elements consistent with Arnab's taxonomy. 
The findings of the current study are also consistent with earlier research into student interactions in online courses. Much of this research has demonstrated a positive relationship between peer interactions and student engagement and social presence [51-53]. These peer interactions have also been found to increase student learning: "Student engagement increases student satisfaction, enhances student motivation to learn, reduces the sense of isolation, and improves student performance in online courses," [52] (p. 205).

Additionally, Richardson et al. [54] conducted a meta-study that examined moderating factors in social presence in online courses, and reported that " (a) the strength of the relationship between social presence and satisfaction was moderated by the course length, discipline area, and scale used to measure social presence; and (b) the relationship between social presence and perceived learning was moderated by the course length, discipline area, and target audience of the course," [54] (p. 402). Our findings about the emergent social networks and epistemic spaces identified in each key learning activity are consistent with these conclusions.

\subsection{Limitation of the Study}

The limitation of this pilot study is primarily in the small sample size. This study used a convenience sampling method and so was confined to the student and instructor participants enrolled in this course. A further longitudinal study is already under way to compare the findings across four iterations of the graduate teacher education course.

\subsection{Implications and Further Research}

The findings of this pilot case study suggest that there is a positive relationship between the degree of autonomy in learning activities, as viewed through the lens of Arnab's taxonomy of game design elements and Self-Determination Theory (SDT), and patterns of interactions between learners that result in emergent, more decentralized social networks. Additionally, there is a positive relationship between these autonomous components of learning/game design and the epistemic spaces associated with higher levels of autonomy as demonstrating a more active cognitive presence, as evidenced by the expertise network that was present during the Robot Coding learning activity.

Further research is currently underway in the form of a four-year longitudinal study, which is focused on other mediating factors of student self-efficacy on these patterns and types of student interactions.

Author Contributions: Conceptualization, methodology, validation, formal analysis, data curation, original draft preparation, visualization, project administration, G.A. Original draft preparation, writing-review and editing, formal analysis, B.C. All authors have read and agreed to the published version of the manuscript.

Funding: This research received no external funding.

Institutional Review Board Statement: Not applicable.

Informed Consent Statement: Not applicable.

Acknowledgments: The authors wish to acknowledge the support provided by three research assistants, Susan Granta, Alex Muniz and Ezra Friedlander, in the analysis of these data.

Conflicts of Interest: The authors declare no conflict of interest.

\section{References}

1. Salen, K.; Tekinbaş, K.S.; Zimmerman, E. Rules of Play: Game Design Fundamentals; MIT Press: Cambridge, MA, USA, 2004.

2. Kapp, K.M. The Gamification of Learning and Instruction: Game-Based Methods and Strategies for Training and Education; John Wiley \& Sons: Hoboken, NJ, USA, 2004.

3. Kim, S.; Song, K.; Lockee, B.; Burton, J. What is gamification in learning and education? In Gamification in Learning and Education; Springer: Cham, Switzerland, 2018; pp. 25-38.

4. Kelly, K.A. A yearlong general education course using "Reacting to the Past" pedagogy to explore democratic practice. Int. J. Learn. 2009, 16, 147-155. [CrossRef] 
5. Good, B.M.; Su, A.I. Games with a scientific purpose. Genome Biol. 2011, 12, 135. [CrossRef]

6. Uysal, A.; Yildirim, I.G. Self-determination theory in digital games. In Gamer Psychology and Behavior; Bostan, B., Ed.; Springer: Cham, Switzerland, 2016; pp. 123-135.

7. Gee, J.P. Games, learning and 21st century survival skills. J. For. Virtual Worlds Res. 2009, 2. [CrossRef]

8. Proulx, J.N.; Romero, M.; Arnab, S. Learning mechanics and game mechanics under the perspective of self-determination theory to foster motivation in digital game-based learning. Simul. Gaming 2017, 48, 81-97. [CrossRef]

9. Ryan, R.M.; Deci, E.L. Self-determination theory and the facilitation of intrinsic motivation, social development and well-being. Am. Psychol. 2000, 55, 68-77. [CrossRef]

10. Chen, B.; Vansteenkiste, M.; Beyers, W.; Boone, L.; Deci, E.L.; Van der Kaap-Deeder, J.; Duriez, B.; Lens, W.; Matos, L.; Mouratidis, A.; et al. Basic psychological need satisfaction, need frustration, and need strength across four cultures. Motiv. Emot. 2015, 39, 216-236. [CrossRef]

11. Vansteenkiste, M.; Ryan, R.M.; Soenens, B. Basic psychological need theory: Advancements, critical themes and future directions. Motiv. Emot. 2020, 44, 1-31. [CrossRef]

12. Wannheden, C.; Stenfors, T.; Stenling, A.; von Thiele Schwarz, U. Satisfied or frustrated? A qualitative analysis of need satisfying and need frustrating experiences of engaging with digital health technology in chronic care. Front. Public Health $2021,8,1097$. [CrossRef]

13. Levesque-Côté, J.; Fernet, C.; Morin, A.J.; Austin, S. On the motivational nature of authentic leadership practices: A latent profile analysis based on self-determination theory. Leadersh. Organ. Dev. J. 2020, 42, 178-194. [CrossRef]

14. Sheldon, K.M. Catholic guilt? comparing catholics' and protestants' religious motivations. Int. J. Psychol. Relig. 2006, 216, 209-223. [CrossRef]

15. Jeno, L.M.; Vandvik, V.; Eliassen, S.; Grytnes, J.A. Testing the novelty effect of an m-learning tool on internalization and achievement: A self-determination theory approach. Comput. Educ. 2019, 128, 398-413. [CrossRef]

16. Howard, J.L.; Bureau, J.S.; Guay, F.; Chong, J.X.Y.; Ryan, R.M. Student motivation and associated outcomes: A meta-analysis from self-determination theory. Perspect. Psychol. Sci. 2021. [CrossRef]

17. Taylor, G.; Jungert, T.; Mageau, G.A.; Schattke, K.; Dedic, H.; Rosenfield, S.; Koestner, R. A self-determination theory approach to predicting school achievement over time: The unique role of intrinsic motivation. Contemp. Educ. Psychol. 2014, 39, 342-358. [CrossRef]

18. Wang, C.J.; Liu, W.C.; Kee, Y.H.; Chian, L.K. Competence; autonomy, and relatedness in the classroom: Understanding students motivational processes using the self-determination theory. Heliyon 2019, 5, e01983. [CrossRef]

19. Niemiec, C.P.; Ryan, R.M. Autonomy, competence, and relatedness in the classroom: Applying self-determination theory to educational practice. Theory Res. Educ. 2009, 7, 133-144. [CrossRef]

20. Rigby, C.S.; Ryan, R.M. Glued to Games: How Video Games Draw Us in and Hold Us Spellbound; Praeger: Santa Barbara, CA, USA, 2011.

21. Peng, W.; Lin, J.; Pfeiffer, K.; Winn, B. Need satisfaction supportive game features as motivational determinants: An experimental study of a self-determination theory guided exergame. Media Psychol. 2012, 15, 175-196. [CrossRef]

22. Ryan, R.M.; Rigby, C.S.; Przybylski, A. The motivational pull of video games: A self-determination theory approach. Motiv. Emot. 2006, 30, 344-360. [CrossRef]

23. Arnab, S.; Lim, T.; Carvalho, M.B.; Bellotti, F.; De Freitas, S.; Louchart, S.; Suttie, N.; Berta, R.; De Gloria, A. Mapping learning and game mechanics for serious games analysis. Br. J. Educ. Technol. 2015, 46, 391-411. [CrossRef]

24. Kemp, J.E.; Morrison, G.R.; Ross, S.M. Designing Effective Instruction, 7th ed.; John Wiley \& Sons: Hoboken, NJ, USA, 2012.

25. White, N. Gamification, an Instructional Strategy to Course Design and Impact on Learning Outcomes. Ph.D. Thesis, Capella University, Minneapolis, MN, USA, 2020.

26. Wardaszko, M.; Podgórski, B. Mobile learning game effectiveness in cognitive learning by adults: A comparative study. Simul. Gaming 2017, 48, 435-454. [CrossRef]

27. Bonde, M.T.; Makransky, G.; Wandall, J.; Larsen, M.V.; Morsing, M.; Jarmer, H.; Sommer, M.O.A. Improving biotech education through gamified laboratory simulations. Nat. Biotechnol. 2014, 32, 694-697. [CrossRef]

28. Koivisto, J.; Hamari, J. The rise of motivational information systems: A review of gamification research. Int. J. Inf. Manag. 2019, 45, 191-210. [CrossRef]

29. Korte, G.; Ferri, G. Research through game design: Interactive stories from a submerged Amsterdam. Ocula 2018, 19, 110-128. [CrossRef]

30. Garcia, A. Inform, perform, transform: Modeling in-school youth participatory action research through gameplay. Knowl. Quest 2012, 41, 46.

31. Walsh, C. Systems-based literacy practices: Digital games research, gameplay and design. Aust. J. Lang. Lit. 2010, 33, 24-40.

32. Dron, J.; Ostashewski, N. Seeking connectivist freedom and instructivist safety in a mooc. Educación XX1 2015, 18, 51-76. [CrossRef]

33. Bayliss, J.D.; Schwartz, D.I. Instructional design as game design. In Proceedings of the 4th International Conference on Foundations of Digital Games, New York, NY, USA, 26-30 April 2009; pp. 10-17.

34. Borgatti, S.P.; Mehra, A.; Brass, D.J.; Labianca, G. Network analysis in the social sciences. Science 2009, 323, 892-895. [CrossRef]

35. Granovetter, M. The strength of weak ties: A network theory revisited. Sociol. Theory 1983, 1, 201-233. [CrossRef] 
36. Canossa, A.; Harteveld, C. Social network analysis applied to game communities to identify key social players. In Data Analytics Applications in Gaming and Entertainment; CRC Press: Boca Raton, FL, USA, 2019; pp. 169-182.

37. Pirker, J.; Rattinger, A.; Drachen, A.; Sifa, R. Analyzing player networks in Destiny. Entertain. Comput. 2018, 25, 71-83. [CrossRef]

38. Amrit, C.; ter Maat, J. Understanding information centrality metric: A simulation approach. arXiv 2018, arXiv:1812.01292.

39. Fruchterman, T.M.J.; Reingold, E.M. Graph drawing by force-directed placement. Softw. Pract. Exp. 1991, 21, 1129-1164. [CrossRef]

40. Kalamaras, D. Social Network Visualizer (SocNetV). Available online: http:/ / socnetv.sourceforge.net (accessed on 1 June 2021).

41. Corbin, J.; Strauss, A. Basics of Qualitative Research: Techniques and Procedures for Developing Grounded Theory; Sage Publishing: Thousand Oaks, CA, USA, 2014.

42. Shaffer, D.W. Quantitative Ethnography; Cathcart Press: Madison, WI, USA, 2017.

43. Shaffer, D.W. Epistemic network analysis: Understanding learning by using big data for thick description. In International Handbook of the Learning Sciences; Fischer, F., Hmelo-Silver, C.E., Goldman, S.R., Reimann, P., Eds.; Routledge: New York, NY, USA, 2018; pp. 520-531.

44. Vujovic, M.; Amarasinghe, I.; Hernández-Leo, D. Studying collaboration dynamics in physical learning spaces: Considering the temporal perspective through epistemic network analysis. Sensors 2021, 21, 2898. [CrossRef]

45. Bressler, D.M.; Bodzin, A.M.; Eagan, B.; Tabatabai, S. Using epistemic network analysis to examine discourse and scientific practice during a collaborative game. J. Sci. Educ. Technol. 2019, 28, 553-566. [CrossRef]

46. Ducheneaut, N.; Yee, N.; Nickell, E.; Moore, R.J. “Alone together?" Exploring the social dynamics of massively multiplayer online games. In Proceedings of the SIGCHI Conference on Human Factors in Computing Systems, Montreal, QC, Canada, 22-26 April 2006; pp. 407-416.

47. Hamari, J.; Keronen, L. Why do people play games? A meta-analysis. Int. J. Inf. Manag. 2017, 37, 125-141. [CrossRef]

48. Hsiao, C.C.; Chiou, J.S. The effects of a player's network centrality on resource accessibility, game enjoyment, and continuance intention: A study on online gaming communities. Electron. Commer. Res. Appl. 2012, 11, 75-84. [CrossRef]

49. Williams, D.; Ducheneaut, N.; Xiong, L.; Zhang, Y.; Yee, N.; Nickell, E. From tree house to barracks: The social life of guilds in World of Warcraft. Games Cult. 2006, 1, 338-361. [CrossRef]

50. Van de Bovenkamp, R.; Shen, S.; Jia, A.L.; Kuipers, F. Analyzing implicit social networks in multiplayer online games. IEEE Internet Comput. 2014, 18, 36-44.

51. Bettinger, E.; Liu, J.; Loeb, S. Connections matter: How interactive peers affect students in online college courses. J. Policy Anal. Manag. 2016, 35, 932-954. [CrossRef]

52. Martin, F.; Bolliger, D.U. Engagement matters: Student perceptions on the importance of engagement strategies in the online learning environment. Online Learn. 2018, 22, 205-222. [CrossRef]

53. Truhlar, A.M.; Walter, M.T.; Williams, K.M. Student engagement with course content and peers in synchronous online discussions. Online Learn. 2018, 22, 289-312. [CrossRef]

54. Richardson, J.C.; Maeda, Y.; Lv, J.; Caskurlu, S. Social presence in relation to students' satisfaction and learning in the online environment: A meta-analysis. Comput. Hum. Behav. 2017, 71, 402-417. [CrossRef] 